СПИСОК ЛИТЕРАТУРЫ

1. Андрющенко С.А., Васильченко М.Я., Трифонова E.H. Факторы повышения эффективности производственного потенциала молочного скотоводства и молочной промышленности России // Аграрный научный журнал. - 2018. - № 5. - С. 59-66.

2. Баутин В.М. Концептуальные основы формирования инновационной экономики в агропромышленном комплексе России. - М.: Изд-во РГАУ - МСХА, 2012. - 165 с.

3. Васильченко М.Я. Региональные особенности инновационного развития российского молочного скотоводства // Аграрный научный журнал. - 2016. - № 12 - С. 70-77.

4. Голубев А.В. Импортозамещение на агропродовольственном рынке России: намерения и возможности // Вопросы экономики. - 2016. - № 3. - С. 46-62.

5. Инновационная деятельность в аграрном секторе экономики России / И.Г. Ушачев [и др.]; под ред. И.Г. Ушачева, И.Т. Трубилина, Е.С. Оглоблина, И.С. Санду. - М.: КолосС, 2007. - 374 c.

6. Козлов В.В., Козлова Е.Ю. Сельскохозяйственная консультационная деятельность: региональный аспект. - М.: Росинформагротех, 2010 - 183 с.

7. Организация инновационной деятельности в АПК / В.И. Нечаев [и др.]; под ред. В.И. Нечаева. - М.: КолосС, 2012. - 296 с.

8. Оценка технической эффективности методом анализа оболочки данных. - Режим доступа: http://www. dea-analysis.com/.

9. Сазонова Д.Д., Сазонов С.Н. Аллокативная и техническая эффективности фермерских хозяйств. Серия «Научные доклады: независимый экономический анализ», № 208. - М.: Московский общественный научный фонд; АНО «Независимый экономический аналитичес- кий центр по проблемам деятельности крестьянских (фермерских) хозяйств», 2010. - 160 с.

10. Уколов А.И. Конкурентоспособность и эффективность аграрных бизнесов // Вестник Саратовского госагроуниверситета им. Н.И. Вавилова. - 2012. - № 9. - С. 102-107.

11. Фастова Е.В.Структура себестоимости 1 кг молока // DairyNews.ru. -2013. - №2. - Режим доступа: http:// www.dairynews.ru/dairyfarm/struktura-sebestoimosti-1kg-moloka.html.

12. Чаянов A.B. Основные идеи и методы работы Общественной Агрономии; изд. 3-е доп. и перер. - М.: издательство Наркомзема «Новая деревня», 1924. - 123 с.

13. Farrel J. Michael (1957). The measurement of Productive efficiency // Journal of the Royal Statistical Society, Series A, General 125, Part 2: P. 252-267.

14. Rogers Everett (16 August 2003). Diffusion of Innovations, 5th Edition. Simon and Schuster: P. 576.

15. Van den Ban, A.W. and Hawkins, H.S. (1966). Agricultural Extension, Second edition, Blackwell Science LTD, Oxford: P. 293.

Уколов Андрей Игоревич, старший преподаватель кафедры «Финансы», Российский государственный аграрный университет - МСХА имени К.А. Тимирязева. Россия.

Козлов Вячеслав Васильевич, $\partial-p$ экон. наук, проф. кафедры «Управление», Российский государственный аграрный университет - МСХА имени К.А. Тимирязева. Россия.

127550, г. Москва, ул. Тимирязевская, 49.

Тел.: 89859807782.

Ключевъе слова: оценка инновационного потенциала; молочное скотоводство; трансфер инноваций; технологии производства; реализация продукции; производительность труда.

\title{
THE DAIRY CATTLE BREEDING INNOVATIVE POTENTIAL ASSESSMENT
}

Ukolov Andrey Igorevich, Senior Teacher of the chair "Finance”, Russian State Agrarian University - Moscow Agricultural Academy named after K.A. Tymyryazev. Russia.

Kozlov Vyacheslav Vasilyevich, Doctor of Economic Sciences, Professor of the chair "Management", Russian State Agrarian University - Moscow Agricultural Academy in honor of K.A. Tymyryazev. Russia.

Keywords: innovative potential assessment; dairy cattle breeding; innovation transfer; production technologies; product sale; productivity.
The article discloses fairly simple tools ranking of agricultural producers by their degree of readiness to the perception and implementation of innovations on the basis of the integral estimates key production and financial capacities. This toolkit can be used not just for businesses but for territorial entities. The capabilities of this tool are demonstrated on the dairy cattle breeding example.

DOI

удк 631:316.48:33

\section{СОВРЕМЕННОЕ СОСТОЯНИЕ И ОСНОВНЫЕ ПРОБЛЕМЫ СОЦИАЛЬНОГО И ЭКОНОМИЧЕСКОГО РАЗВИТИЯ СЕЛЬСКИХ ТЕРРИТОРИЙ САРАТОВСКОЙ ОБЛАСТИ}

\author{
ЮРКОВА Марина Сергеевна, Поволжский научно-исследовательский институт экономики \\ и организации АПК \\ ТРОФИМОВА Валентина Ивановна, Поволжский научно-исследовательский институт \\ экономики и организации АПК
}

ГОЛУБЕВА Анна Алексеевна, Поволжский научно-исследовательский институт экономики и организации АПК

Проанализировано состояние социально-экономического развития сельских территорий Саратовской области. Охарактеризовано природно-климатическое различие Левобережъя и Правобережъя. Предложены основные направления совериенствования социально-экономического развития сельских территорий региона с точки зрения мер, касающихся правового обеспечения, развития экономики и социального партнерства на селе.

Введение. Экономическое развитие сельских территорий напрямую зависит от состояния агропромышленного комплекса региона и основано на использовании природно-ресурсного и производственного потенциала. Климатические особенности Саратовской области и достаточно большая пло- 
щадь региона обусловливают развитие как растениеводства, так и животноводства. Большое разнообразие природно-экономических условий вызвало необходимость деления региона на две существенно различающиеся между собой зоны, разделенные руслом реки Волги (Право- и Левобережье) [11]. В Правобережной зоне, где природно-климатические условия носят выровненный характер по годам, а количество осадков минимально достаточно, преобладают предприятия зерново-скотоводческого направления с развитым производством технических культур и картофеля, а также хозяйства, занимающиеся свиноводством и птицеводством. Левобережная зона, отличающаяся крайней засушливостью и менее плодородными почвами, специализируется на зерне (пшенице яровых сортов твердых и сильных видов, ячмене, озимых сортах пшеницы), овощах, ряде технических культур, овцеводстве и птицеводстве. Всё это предопределяет различия в социально-экономическом развитии сельских территорий данных зон и в целом области.

Методика исследований. На сегодняшний день теория и методология проблемы развития социальных и экономических отношений на селе разработана в трудах ученых-экономистов $[1,4]$. Недостаток государственного регулирования процессов развития и совершенствования социальных и экономических отношений на селе и финансового обеспечения на поиск направлений изменений, необходимых как в системе экономических, так и в системе социальных связей и отношений в аграрном производстве и в повседневной жизни граждан сельских территорий.

Цель исследования - проанализировать современное состояние социального и экономического развития сельских территорий Саратовской области, выявить основные проблемы и дать рекомендации по направлениям улучшения и совершенствования сложившейся ситуации на селе.

Теоретическую, методологическою и информационную базу исследования составили работы отечественных и зарубежных ученых, посвященные различным аспектам развития социальных и экономических отношений на селе, определению эффективности их основных форм, данные Госкомстата, Минэкономразвития и Минсельхоза РФ и регионов Поволжья, федеральные, региональные и муниципальные нормативно-правовые акты, программы, материалы министерства здравоохранения Саратовской области. Основные методы исследования: статистико-экономический, монографический, абстрактно-логический, расчетно-конструктивный.

Резулътаты исследований. Развитость агропромышленного комплекса региона предполагает значительное число сельхозпредприятий всех форм собственности. Однако в последние годы наметилась тенденция сокращения сельхозпредприятий. Особенно сильно снизилось число крупных предприятий всех форм собственности. Незначительное увеличение наблюдалось только по ИП
Главам К $(\Phi) \mathrm{X}, \mathrm{OOO}$ и прочим предприятиям, которые в силу объективных причин, не могут создать большое число рабочих мест и обеспечить работой всех желающих. Такая ситуация негативно сказывается на занятости населения в сельской местности и приводит к росту безработицы. За последние годы среднесписочная численность работников в сельхозпредприятиях Саратовской области снизилась на 715 человек, а численность работников в К $(\Phi) X$ на 95 человек [9].

Продолжающийся процесс переоснащения аграрного сектора современной техникой вызвал рост производительности труда и, как следствие, сокращение потребности в работниках. Так, за последние годы, по данным годовых бухгалтерских отчетов регионального минсельхоза, в Саратовской области с 2010 по 2015 гг. площадь обрабатываемой пашни на 1 механизатора выросла в 1,4 раза с 349 до 494 га [6]. При этом уровень оплаты труда работников, занятых в сельском хозяйстве, остается невысоким. Среднемесячная заработная плата работников сельскохозяйственных организаций в среднем за 2014-2016 гг. составила 14423,7 руб., в пищевых организациях - 16349,5 руб. Саратовская область отстает в уровне оплаты труда работников сельского хозяйства от средних показателей Приволжского федерального округа и РФ [6].

Нехватка рабочих мест и низкий уровень оплаты труда вызывает миграцию населения из небольших сел в более крупные города и другие регионы [12]. Отток трудоспособного сельского населения оказывает влияние на снижение количества родившихся и естественную убыль населения. В свою очередь, эти процессы находят отражение в сокращении численности населения Саратовской области [9]. К 2017 г. численность населения региона снизилась до 2479,3 тыс. человек. При этом сельское население сократилось до 607,1 тыс. человек [9]. Снижение численности населения приводит к вымиранию многих сел и сокращению количества сельских поселений.

Ввод в действие объектов социального и инженерного обустройства в сельской местности идет достаточно медленными темпами, что также не способствует заинтересованности людей в жизни на селе. На сельских территориях в 2014-2015 гг. не было введено в эксплуатацию ни одного объекта общеобразовательных и дошкольных учреждений. К 2016 г. в сельской местности насчитывалось 606 школ (66,8 \% от общего количества школ), в которых обучалось более 50,8 тыс. детей (22,8 \% от общей численности школьников) [5]. Возможность участия в соцпартнерстве предприятий и населения области помогает улучшить сложившуюся ситуацию, так например, в поселке Ивановский Саратовского района в 2016 г. на спонсорские средства при школе создана разновозрастная дошкольная группа на 25 мест. В 2017 г. введены в эксплуатацию 3 сельских школы (Саратовского, Энгельсского и Ровенского районов) [5]. 
В настоящее время практически прекращено строительство сельских клубов. Остро стоит проблема ввода новых и ремонта существующих фельдшерско-акушерских пунктов, в связи с чем, для сельского населения медицинские услуги менее доступны, чем для горожан. Несмотря на то, что с 2012г. в области построено 17 фельшерско-акушерских пункта (ФАП), в том числе в 2017 г. - ФАП в селе Успенка Пугачевского района, а в 2018 г. планируется построить ФАП в селе Привольное Ровенского района, ситуация остается напряженной $[3,10]$.

Общая протяженность автомобильных дорог общего пользования регионального значения на территории Саратовской области по состоянию на 01.01.2017 г. составляет 7204,2 км. Из этого количества не отвечает нормативным требованиям 91 \% дорог области. Неразвитость инфраструктуры, ограниченность сферы применения труда и низкая заработная плата ведут к снижению привлекательности жизни и работы на сельских территориях региона [13].

Результаты анализа современного состояния развития сельских территорий свидетельствуют о том, что основу социальных и экономических отношений на селе формируют отношения собственности на землю. Земля является главным средством производства в сельском хозяйстве и, согласно теории К. Маркса, совместно с трудом и капиталом, основой всякого богатства $[4,16]$. Одновременно, земля как фактор производства формирует основополагающие экономические отношения. В регионе площадь земли в собственности сельхозорганизаций увеличилась за 2011-2015 гг. до 708364 га, а площадь земель в аренде - до 2127324 га. Площадь земли, находящейся в стадии оформления, уменьшается, но основная часть всей обрабатываемой пашни (72,1 \%) находится в аренде [6].

Практический опыт социальных и экономических отношений был рассмотрен авторами на примере Саратовской области (в Пугачевском, Краснокутском, Марксовском, Екатериновском и Турковском районах) с учетом основных организационно-правовых форм сельскохозяйственных предприятий. При этом были выявлены основные проблемы функционирования и развития механизмов эффективных форм социальных и экономических отношений на селе во взаимосвязи с основными субъектами этих отношений: организациями различных форм собственности и размеров, сельским населением и администрациями районов [15].

Общие проблемы большинства предприятий всех организационно-правовых форм: отсутствие эффективных трудовых договоров с работниками, применение непостоянной (сезонной) занятости, оформление работников в основном по МРОТ с включением механизма «серой» зарплаты, минимальные социальные гарантии по ТК РФ. Кроме этого в К(Ф)Х, как у основных представителей малых форм хозяйствования существуютпроблемы отсутствия социальных гарантий и гибкого механизма альтернативных форм занятости (диверсификации производства) во внесезонный период, недоброжелательное отношение к профсоюзам. Проблемами коллективных хозяйств в большинстве случаев являются сложности с гармонизацией договорных отношений, отсутствие внутренних социальных программ, эффективного механизма выделения средств на социальное развитие села и текущие проблемы сельских территорий, нет стимулирующего фактора развития социального партнерства $[14,15]$.

В интегрированных предприятиях не налажен эффективный механизм выделения средств на социальное партнерство с учетом планирования прибыли или затрат на развитие социальной инфраструктуры как необходимого элемента сельскохозяйственного производства на селе. Таким образом, внедряя механизмы эффективных форм социальных и экономических отношений на селе, в том числе инновации, мы будем целенаправленно воздействовать на решение всех этих проблем и совершенствовать социально-экономическое развитие сельских территорий $[2,7,8]$.

На наш взгляд, с учетом того, что современный уровень финансирования государственных программ развития сельских территорий недостаточен по сравнению с необходимыми объемами, направления совершенствования социально-экономического развития села должны напрямую зависеть от величины и, соответственно, возможностей предприятий, работающих на селе. Нами был проведен анализ малых и коллективных предприятий аграрной сферы региона.

В рамках исследования малых форм хозяйствования были составлены группировки К $(\Phi) \mathrm{X}$ и ИП с разбивкой на Правобережье и Левобережье. На сегодняшний день в Правобережных более благоприятных по природно-климатическим условиям районах функционирует 850 таких предприятий, тогда как в Левобережных менее благоприятных районах - 645 хозяйств. Все малые предприятия области были поделены на группы по численности работников (в том числе сезонных и временных), по площади земельных угодий и величине доходов. Ниже приведены данные по группам малых предприятий в зависимости от величины доходов (табл. 1) [6, 14].

Данные табл. 2 показывают, что в 2016 г. доход владельцев - членов К(Ф)Х, которых насчитывалось 1764 чел., составил свыше 20 млрд 935 млн руб., в том числе от реализации сельскохозяйственной продукции 19 млрд 331 млн руб., из которых на растениеводство пришлось 17 млрд 339 млн руб. $(89,7 \%)$ и 783 млн руб. (4 \%) на животноводство.

Примечательно, что К $(\Phi) Х$ с доходом свыше 120 млн руб. в Правобережье насчитывается 6 хозяйств (0\%), тогда как в Левобережье 16 (2,2 \%). В дальнейшей перспективе, по нашему мнению, в Левобережных районах малые предприятия сформируются в более крупные как по площади пашни, так и по доходности. 
Группировка предприятий малых форм хозяйствования Саратовской области по величине дохода, тыс. руб. на 1 предприятие

\begin{tabular}{|c|c|c|c|c|c|}
\hline \multirow{2}{*}{ Показатель } & \multirow{2}{*}{ Всего } & \multicolumn{4}{|c|}{ Доход, млн руб. на 1 предприятие } \\
\hline & & до 5,0 & $5,0-50$ & $50-120$ & более 120 \\
\hline Область, число хозяйств, ед. & 1535 & 825 & 615 & 73 & 22 \\
\hline В \% к общей численности предприятий & 100,0 & 53,7 & 40,1 & 4,7 & 1,4 \\
\hline Общая сумма доходов & 20935,8 & 1559,5 & 9361,0 & 5612,7 & 4402,6 \\
\hline В \% к общей сумме доходов & 100,0 & 7,5 & 44,7 & 26,8 & 21,0 \\
\hline Правобережье, число хозяйств, ед. & 876 & 424 & 405 & 41 & 6 \\
\hline В \% к общей численности предприятий & 100,0 & 48,4 & 46,2 & 4,7 & 0,7 \\
\hline Общая сумма доходов & 11272,2 & 844,0 & 6146,3 & 3148,8 & 1133,1 \\
\hline В \% к общей сумме доходов & 100,0 & 7,5 & 54,5 & 27,9 & 10,1 \\
\hline Левобережье, число хозяйств, ед. & 657 & 400 & 209 & 32 & 16 \\
\hline В \% к общей численности предприятий & 100,0 & 60,9 & 31,8 & 4,9 & 2,4 \\
\hline Общая сумма доходов & 9655,4 & 712,5 & 3209,5 & 2464, & 3269,5 \\
\hline В \% к общей сумме доходов & 100,0 & 7,4 & 33,2 & 25,5 & 33,9 \\
\hline
\end{tabular}

ленностью работников свыше 15 человек, включая и членов К(Ф)Х, которых по области 111 с общей численностью работающих 3686 человек, очевидно, следует рекомендовать перспективы перехода в другую организационно-правовую форму в соответствии ГК РФ. Соответственно, работники получат все права и социальные гарантии, предусмотренные ГК РФ, ТК, соглашениях и договорах социальной направленности, смогут полноценно участвовать в работе профсоюзных и общественных организаций.

В исследовании также были рассмотрены коллективные предприятия аграрной сферы, которые при проведении анализа социальноэкономического положения были разделены на 3 группы (табл. 2) [14, 15]. При этом 52 предприятия не были учтены нами в данной группировке по чистой прибыли, так как получили убыток в 2016 г. и являются объектами социальной нагрузки для более прибыльных предприятий.

Таким образом, в первую группу с низким уровнем чистой прибыли, вошло больше половины всех учтенных предприятий или 59,6 \% (272 предприятия). Хозяйства со средним уровнем чистой прибыли вошедшие во вторую группу занимают 29,3 \% в общей численности, с долей дохода 34,6 \%. Третья группа насчитывает 50 хозяйств, которые составляют 11,1 \% от общей численности и являются наиболее состоятельными, их доход занимает 56,9 \% от общего дохода в структуре. Из 456 сельскохозяйственных предприятий региона, средствами на социальное развитие села потенциально обладают всего 50 хозяйств или чуть больше 1/10 части всех хозяйств. Предприятия средней группы тоже могут выделять средства на развитие инфраструктуры села, но это более проблематично увязать с целями воспроизводственного процесса в этих хозяйствах [15].

Таблица 2 онно-правовые формы согласно ГК РФ. При этом такие проблемы, как неформальная занятость, выплаты «серых» зарплат, неуплаты в пенсионный и страховые фонды значительно бы сократились.

Для решения этих проблем, по нашему мнению, необходимо:

рассмотреть возможность законодательно обязать фермеров, предоставлять органам Росстата информацию по тем же формам и показателям, что и подведомственные Минсельхозу области предприятия;

К(Ф)Х, которые, согласно Постановления № 858 от 27 августа 2016 г., имеют среднюю среднегодовую численность работников за предыдущий год менее 15, должны применять типовой трудовой договор в соответствии с этим постановлением;

ность участия в социальном партнерстве на селе.

\section{Саратовской области по величине чистой прибыли (после налогообложения)}

\begin{tabular}{|c|c|c|c|c|}
\hline \multirow[b]{2}{*}{ Показатель } & \multirow[b]{2}{*}{ Всего } & \multicolumn{3}{|c|}{$\begin{array}{c}\text { Величина чистой прибыли } \\
\text { на } 1 \text { хозяйство }\end{array}$} \\
\hline & & 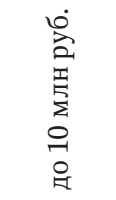 & 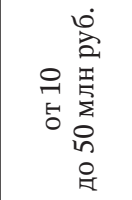 & 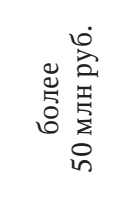 \\
\hline Число хозяйств, ед. & 456 & 272 & 134 & 50 \\
\hline $\begin{array}{l}\text { В \% к общей числен- } \\
\text { ности предприятий }\end{array}$ & 100 & 59,6 & 29,3 & 11,1 \\
\hline $\begin{array}{l}\text { Суммарная прибыль, } \\
\text { млн руб. }\end{array}$ & 8999,029 & 762,668 & 3116,031 & 5120,330 \\
\hline В \% к общей прибыли & 100 & 8,5 & 34,6 & 56,9 \\
\hline
\end{tabular}


Заключение. Исходя из вышеизложенного следует отметить, что для сохранения сельских территорий и поддержания сельской инфраструктуры должны быть, с одной стороны, четко обозначены ресурсы, выделяемые хозяйствами на социальное развитие села и, с другой, - льготы и преференции, которые может предоставить им взамен государство. Социальное развитие сельских территорий касается всех жителей и без посильного участия каждого из них обустройство села невыполнимо.

\section{СПИСОК ЛИТЕРАТУРЫ}

1. Голубева А.А. Особенности эволюционного развития агроэкономики // АПК: Экономика, управление. - 2001. - № 6. - С. 74-77.

2. Голубева А.А., Мурашова А.С. Формирование современной системы консалтинга продвижения инноваций // Никоновские чтения. - 2013. - № 18. C. $105-108$.

3. Информация об итогах деятельности отрасли здравоохранения за 2017 год и приоритетных направлениях развития на 2018 год. - Режим доступа: http:// www.minzdrav.saratov.gov.ru/activities/stat/index. php?SECTION_ID=360\&ELEMENT_ID $=30207$.

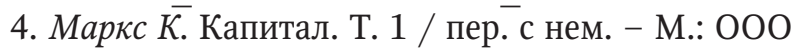
«Издательство» АСТ, 2001. - 699 с.

5. Министерство образования Саратовской области. Аналитическая справка: «Совершенствование системы высшего образования Саратовской области». Саратов, 2016. - 36 c.

6. Министерство сельского хозяйства Саратовской области: официальный сайт. - Режим доступа: http://minagro.saratov.gov.ru/.

7. Провидонова Н.В., Санникова М.О. Инновационное развитие сельскохозяйственного производства Саратовской области: тенденции и направления роста. - Саратов, 2017. - 96 с.

8. Санникова М.О., Провидонова Н.В. Государственно-частное партнерство как форма активизации инновационно-технического развития сельскохозяйственного производства // Аграрный научный журнал. - 2018. - № 1. - С. 74-80.

9. Саратовская область в цифрах - 2015: краткий статистический сборник / Территориальный орган Федеральной службы государственной статистики по Саратовской области. - Саратов, 2016. - 263 с.

10. Трофимова В.И. Актуальные проблемы развития сельских территорий на региональном уровне // Островские чтения. - 2017. - № 1. - С. 551-556.
11. Трофимова В.И. Зональные особенности аграрного производства Саратовской области // Тенденции и закономерности развития АПК России: национальный и международный аспекты: материалы Междунар. науч.-практ. конф. - Саратов, 2017. - С. 106-109.

12. Трофимова В.И., Грачева Л.А. Некоторые пути повышения занятости и доходов сельского населения // Сельская бедность: причины и пути преодоления. Никоновские чтения. - 2004. - С. 125.

13. Фирсов А.И., Трофимова В.И. Улучшение состояния сельских территорий и диверсификации сельской экономики // Организационно-экономический механизм устойчивого развития агропромышленного комплекса и сельских территорий в Поволжье / Е.Ф. Заворотин [и др.]; ФГБНУ «ПНИИЭО АПК». Саратов: Издательство «Саратовский источник», 2017. - С. 218-247.

14. Фирсов А.И., Юркова М.С., Голубева А.А. Совершенствование социальных и экономических отношений на селе // Научное обозрение: теория и практика. - 2018. - № 1. - С. 113-126.

15. Юркова М.С., Голубева А.А., Провидонова Н.В. Обеспечение функционирования механизма эффективных форм социальных и экономических // Научное обозрение: теория и практика. - 2018. - № 2. C. 66-75.

16. Iurkova $M . \mathcal{E}$ Serdobintsev $D$. Increase in investment appeal and competitiveness of agrarian and industrial complex of Volga region. // Perspectives. - 2016. - 2. p. 49-63. - URL: http://perspectives-ism.eu/ contents/22016-2/22016-049-iurkova/.

Юркова Марина Сергеевна, канд. экон. наук, доиент, главный научный сотрудник сектора развития сельских территорий, Поволжский научно-исследовательский институт экономики и организации АПК. Россия.

Трофимова Валентина Ивановна, канд. с.-х. наук, старший научный сотрудник сектора развития сельских территорий, Поволжский научно-исследовательский институт экономики и организации АПК. Россия.

Голубева Анна Алексеевна, канд. экон. наук, доиент, стариий научный сотрудник сектора, Поволжский научно-исследовательский институт экономики и организации АПК. Россия.

410010, г. Саратов, ул. Шехурдина, 12.

Тел.: 89276216274.

Ключевые слова: сельские территории; социальное и экономическое развитие; группировки предприятий; трудовые договора.

\section{CURRENT STATUS AND MAIN PROBLEMS OF SOCIAL AND ECONOMIC DEVELOPMENT OF RURAL AREAS OF THE SARATOV REGION}

Yurkova Marina Sergeevna, Candidate of Economic Sciences, Associate Professor, Chief Researcher of the rural development sector, Volga Research Institute of Economy and Organization of the Agro-industrial Complex. Russia.

Trofimova Valentina Ivanovna, Candidate of Economic Sciences, Associate Professor, Senior Researcher of the rural development sector, Volga Research Institute of Economy and Organization of the Agro-industrial Complex. Russia.

Golubeva Anna Alekseevna, Candidate of Economic Sciences, Associate Professor, Senior Researcher of the rural development sector, Volga Research Institute of Economy and Organization of the Agro-industrial Complex. Russia.
Keywords: rural areas; social and economic development; groupings of enterprises; employment contracts.

The article analyzes the state of socio-economic development of rural areas in the Saratov region. The natural and climatic difference between the Left Bank and the Right Bank is characterized. The main directions of improving social and economic development of rural areas of the region are proposed in terms of measures related to legal support, economic development and social partnership in the countryside. 